\title{
Nature and Socio-Cultural Practices of Social Amnesia in Russian Society
}

\section{Sergey Alexandrovich Dyuzhikov}

\author{
Southern Federal University, Rostov-on-Don, Russian Federation, \\ Pushkinskaya Street, 160, Rostov-on-Don, Russian Federation , 344005 \\ Rashid Dumalichevich Hunagov \\ Adyghe State University, Maikop, Russian Federation. \\ Magomedgabib Gasanhanovich Magomedov
}

Donskoy State Technical University, Rostov-on-Don, Russian Federation

Doi:10.5901/mjss.2015.v6n3s3p31

\author{
Aues Mukhamedovich Kumykov \\ Kabardino-Balkaria State University, Nalchick, Russian Federation
}

\begin{abstract}
The purpose of this article is to identify the means of social and philosophical analysis of the nature and trajectory of the past in the reception of practices for manifestations of social amnesia. The phenomenon of social amnesia is ontologically inscribed in the social reality and is particularly pronounced in periods of social and cultural crisis. It is the reason why the configuration of manifestations of social memory in the characteristics of the national historical process becomes cyclically-wave in nature, when periodically lost contents of memory can go back to history in processed form, responding to the requests of the era and the political class. As memory serves as "the guardian of the past" and a repository of information about the past, the story, which reveals the memory loss, is associated with it or with nostalgia for the past. As a result, social memory, having functional and structural-informative features, includes not only the processes of remembering, but of forgetting, and the nature and trajectory of the reception of the past in contemporary socio-cultural practices, constituting that the essence of social amnesia is peculiar for the deformed character.
\end{abstract}

Keywords: nature, socio-cultural practices, social amnesia, perception of the past, socio-cultural practices.

\section{Introduction}

Russian society is living through one of the most difficult periods in its long history of solving problems overcoming the legacy of totalitarian authoritarian mode of social life through the transformation and modernization. Reflexive and critical potential "questioning" about the experience of the past constantly feeds the actual socio-philosophical discourse, and update of the concept sphere occurs during the transition period, characterized by the unstable society.

History being event-driven in time and space is always closely associated with such changes, transforming modern intellectual "field" of social and philosophical reflection and providers, in turn, has significant impact on the formation of a variety of subjects of socio-cultural transformations practices. Any transitional society cannot do without thinking and rethinking the historical experience to the point that it begins to tire of its "traumatic past".

The subject of social and philosophical reflection - a world of social, is the development of individual existence in the coordinates of social dispensation. The acceleration of change and social upheaval in the context of collective memory and historical experience, the strain of social memory, blur, uncertainty and fragmentation of life in the postmodern world are forcing people to remember the past.

With the development of modern information society impact of social memory, as well as the historical past as a whole, on the key trends and trajectories of social development is being intensified, as modern means of mass communication contribute to the dissemination of information of diverse properties. Although memory is never an exact replica of the past; social memory, operating memories of significant events, stories, personalities, are becoming an important tool that defines the present. 
Social memory can accelerate some social processes and, at the same time, slow down or block others. Often there is manifestation of protective social amnesia (from the Greek: a - absence mnesis - flashback) - loss of the ability to store information and reproduce the acquired knowledge, incomplete memories, eliminating the memory of traumatic events of the past. Memory, forgetfulness, social unconsciousness, and the ousting of individual socially relevant stories, fragments, and personalities of historical memory as a social phenomenon and culture appear to be a very significant problem of social and philosophical discourse.

The problems of social memory and social amnesia, which arose in the depths of a real cultural experience, require significant cognitive effort. In the socio-philosophical and humanities research space, there are formed discourses, which, filled with memories and current estimates of past, present, and future, raises the need for new conceptual approaches and encourages the development of other methodological foundations for the analysis of social memory and social amnesia, memory usage including political power structures of "society rollback and drift". No wonder many people repeat the words by Pierre Nora, saying that we now live in an era of memory, however, a specific memory, manipulative, artificial, which actively interfere with state and media, whereby it becomes an ideal breeding ground for historical and political manipulation. If historical knowledge forms a mutual hatred and intolerance, it is non-functional knowledge.

Thus, the relevance of this article is determined by the following factors.

First, this is the need to find the underlying mechanisms that generates and to maintain social space in the memory of the past and the logic of the transformation of social memory in the cultural and historical context.

Second, there is the increasing demand for social themes of memory, which is more related to the renewal of society and the challenges of overcoming "historical ossification».

Third, there is the desire to understand the nature of the manifestations of social amnesia in the reception practices of the past, due to the political actualization of the past.

Fourth, there is the need of social and cultural change occurring deeper reflection in the social and philosophical reflection traumatic past experiences in the space of studying the phenomenon of social amnesia.

\section{Literature Review}

Problems of social amnesia affect a wide range of studies that address various aspects of the topic. Their basis is social memory as an object of interdisciplinary research.

In historical sense, the science investigates patterns in the preservation of historical memory of past events, the various aspects of handling them political power and society. Social psychology analyses the social memory through the prism of the psychological characteristics of individual reflection in memory of socially significant events. Sociologists refer to the social memory in terms of applied research, identifying usually place in the social memory of various events or historical figures.

In the social and humanitarian thought, the basis for studies of social memory includes the ideas of Emile Durkheim collective representations as a body of knowledge, opinions, and behaviours that act as products of social evolution (Durkheim, 1997). Abstracts of the Durkheim's school on the relationship of memory and social community are reflected in the works by Douglas (Douglas, 1986) and P. Connerton (Connerton, 2009).

The study of the social characteristics of individual and social memory devoted to scientific papers by J. Assmann (Assmann, 2000), M. Halbwachs (Halbwachs, 1992), P. Hutton (Hutton, 2004). Basics of research for the "language of memory" are laid by D. Hermann and M. Grunberg.

Analysis of social needs in the past held a British historian D. Lowenthal, "Past is a foreign country" (Lowenthal, 1985). Lowenthal puts socio-cultural role last analysis, dwelling on issues of nostalgia and fear of the past, on the problem of the perception of the near and distant past (Lowenthal, 1998). In 1995, he published an article by Professor B. Zelizer, in which the author attempted to describe the basic methodological principles of the new approach (Zelizer, 1995). Charlotte Linde in her works conducted investigation of the role of memory in the functioning of the organization, as well as an analysis of personal narratives and the conditions under which the personal stories acquire coherence, sequence, and can count on the understanding and acceptance in society (Linde, 1993).

Disclosure, intermedial dynamics of cultural memory is dedicated to the work of A. Erll (Erll, 2008), in which the author concludes that "existing social media circuit events a certain kind of perception determine the perception of similar events in the future" (Vasiliev, 2013).

In the Russian literature, the revealing of the categorical status of the concept of "social memory" is undertaken in the works by O. T. Loyko (Loyko, 2004). Thus, O. T. Loyko's study addresses the issue of social memory through the contradiction between fairly complete an analysis of private concepts of social memory and the need to descriptions of its 
functioning on a qualitatively different philosophical level.

In turn, L. Yu. Logunova comes from the fact that "memory traces stored on the micro-level personal biographies or histories of families and everyday practices at the macro level are in the collective consciousness of community, in mnemonic labels" (Logunov, 2011). Yu. E .Arnautova and A. G. Vasiliev write about politics of memory and memorialization (Vasiliev, 2009).

E. Rozhdestvenskaya and V. Semenova pay attention to the fact that it is the politics of memory, which becomes an argument for the current interests of political elites. Recollection, processing, or forgetfulness are the three points of a continuum that called memory. Memorising practices, "places of memory" and its rituals are designed to resemble the past, provoking lively reactions or indifference, but an appeal to the experience of the last turns, aims to make the past a part of this, to give it meaning. Present here an element of policy in relation to memory frees it from the dictates of history, but finds thereby its social character (Rozhdestvenskaya \& Semenova, 2011).

A. Kleitman comes from the fact that forgetting as a cultural phenomenon is a form of representation of the past in the present, one of the modes of temporality of human existence and society (Kleitman, 2009).

I. Yu. Solomina believes that social memory includes not only the processes of remembering, but of forgetting. Forgetting in this case is social in nature. Social forgetting (amnesia) means a disorder of memory, in which there is forgetfulness, loss of social memory capacity storage (Solomina, 2005).

Renowned sociologist Zh. T. Toshchenko introduces the concept of "mankurtism". In his opinion, this "phenomenon marks the historical forgetfulness, various forms of falsification of the past, ignoring the previously accumulated spiritual wealth, preparation of historical events and processes claims on the interpretation of history in favour of chauvinistic, xenophobic views" (Toshchenko, 2012).

Directly to the problem of social amnesia in Russian society are affected only by individual authors.

Therefore, G. A. Bakiyeva believes that social amnesia occurs when and where, and when there is a gap between the past, present and future. However, it comes periodically as it unloads on the severity of the human past (Bakiyeva, 2002).

I. Yu. Solomina, indicating the problem of "social forgetting" (social amnesia), seeks to identify various forms of social forgetting in the context of three information during the existence of social memory: up to writing, writing and after writing, and draws attention to the role of social forgetting as a regulator balance the volume of social memory in the public consciousness. Forgetting is a regulator of the amount of information in society.

$\mathrm{V}$. L. Romanova comes from the fact that the distortion of history is the displacement of the facts of conscious memory in the collective unconscious, a ban on certain fragments of consciousness. Consequences mean social neuroticism. During the crisis, the system loses conscious memory of the initial events and appeals to the irrational (Historical Memory..., 2002).

As a result, we can say that the development of the concept of social amnesia is just beginning.

Thus, the analysis of the degree of a theme study shows that various aspects of it got deep enough in the development of social and humanitarian knowledge, but as a special socio-philosophical research the topic of social amnesia in Russian society has not yet been considered.

As a result, the relevance of the topic, its complexity and diversity, lack of full scientific elaboration, as well as a significant theoretical and practical significance led to the main purpose and objectives of the study.

\section{Methodology}

Theoretical and methodological framework research are the ideas presented in the works by Russian and foreign authors, having their works in socio-philosophical and sociological areas devoted to the study of various aspects of the phenomenon of social amnesia in relation to the socio-cultural changes.

The methodological basis of the study includes the principles of social philosophy as a transdisciplinary scientific discipline, providing a theoretical generalization of the results of private research and scientific methods of knowledge analysis and synthesis, induction and deduction, abstraction and typing, and the principles of the study of social phenomena in terms of classical and post-non-classical scientific paradigms.

The author's methodology had a significant impact following theoretical approaches:

a) A constructivist approach to the analysis of social amnesia, which includes the study of problems of "invention" of memories, rituals and traditions as a means of social control and legitimation of power and maintaining identities, and the politicization of memory and the "politics of memory"; dependence images of the past from the current interests of the ruling elites;

b) The concept of "social memory" by M. Halbwachs; 
c) The theory of sociology of culture and the concept of the increasingly complex dynamics of social meanings developed by John. Alexander, in line with neo-functionalism.

The proposed theoretical and methodological approaches allow a review of social amnesia as cultural phenomena and sociality on a broad philosophical-cultural background.

\section{Results and Discussion}

Russian society is living through one of the most difficult periods in its history, solving the problems of overcoming the legacy of totalitarian and authoritarian mode of political ordering of life and social life through the transformation and social modernization. Changes taking place in society, and convert modern intellectual "field" of social and philosophical reflection and the "production" of ideas, providing, in turn, a significant impact on the formation of the subject transformations of various social, political, and cultural practices.

Reflexive and critical potential "questioning" for the legacy of experience of the past constantly feeds the actual socio-philosophical discourse. The past is preserved thanks to the memory through the discordance of discursive practices. Any transitional society, trying to find their roots in the past, cannot do without the historical experience. It seems as if it lives in the space between social amnesia and social nostalgia. It is so to the point when it begins to tire with canonized version of history and its traumatic past.

The acceleration of change and social upheaval in the context of collective memory and historical experience, the strain of social memory and mass appeal to the "artificial past" in the trajectories of the interaction of the past and present are doing particularly urgent problem of the relationship of man and society with its past. Vagueness, uncertainty, and fragmentation of life in the postmodern world are forcing people to remember the past inevitably and invariably. Social memory can accelerate certain social processes, and at the same time, impede or negate the other. Quite often manifests and protective social amnesia mean the desire to eliminate the memory of the past traumatic events.

Demand for memory topics is related to fundamental social problems: many talks are about "memory wars", which refers to contemporary debates and controversy surrounding the memory of the historical past. The abundance of traumatic events in modern history, delayed recognition of their importance, the history of fragmentation in the minds of modern man, the acceleration of social time, the collapse of traditional communities and the disappearance of whole classes in the humanities make to address the issues of memory - historical, social, collective.

The problems of social memory are social amnesia, which arose in the depths of real cultural experience, require significant cognitive effort. The space formed by research discourses in humanities, which, filled with memories and current estimates of past, present and future, raises the need for new conceptual approaches, and encourages the development of new methodological basis for the analysis of social memory and social amnesia, including the political use of memory. It is believed that we now live in age of specific, manipulative, artificial memories, which actively interfere with the state and the media, by virtue of which it becomes an ideal breeding ground for historical and political manipulation, and traditional ways of broadcasting vital experience and the usual mechanisms of intergenerational interaction no longer fit for their purpose.

The appeal to the issues of social memory and social amnesia in contemporary Russian society is dictated by considerations related to the peculiarities of their manifestation in the social reality and the need for conceptual development in the modern social knowledge. In the socio-philosophical discourse memory as a social function acts as a historical memory and is inextricably linked with the historical consciousness. The heuristic value of the concept of "memory" is its rich potentialities, as the development of social reality and its design includes. By the same story - a reconstruction of the past, and memory - it is a living link with the past through historical experience.

Drawing attention to the semantic content-uniqueness in the dichotomy of "memory/oblivion", the researchers come from the theoretical and methodological foundations of philosophical conceptualization of the phenomena of memory and forgetting. As memory serves, "the guardian of the past", a kind of repository of information, stories, which reveals the memory, often associated with loss or with nostalgia for the past, is lost.

Problem field of the study of social memory in its relationship with socio-cultural practices allows understanding as the latest form of social activities, regularly reproducible activities are related to social experience accumulates historically behaviour, which is stored in the public consciousness, and is transmitted from generation to generation. By itself, the interpretation of the past, as an important part of learning processes is both a cultural practice that carries a certain sense.

Identification and systematization of the conceptual understanding of the prerequisites of social amnesia allows conceptualizing and formulating the basic concepts of theoretical and methodological construct of socio-philosophical study of the phenomenon. Author's understanding of the social amnesia phenomena in the context of selected theoretical 
and methodological guidance comes from the fact that the concept is "embedded" in a number of other concepts: history, historical past, historical reality, and historical experience. All of these concepts are closely connected with such phenomena as social memory.

Social amnesia leads to disorganization of social memory as a symbolic reconstruction of the past and in the present set of socio-cultural practices engaged in selection and transformation of social information into meaningful knowledge of the past in order to preserve and broadcast cultural experience.

An important role is played by the reception of the past - intercultural interaction of past and present, when, after borrowing by socio-cultural practices, the past is part of the present. However, owing to the contradictory and ambiguous perception, it is inevitably biased interpretation of the political elites and various social groups, events, stories and images of the past, which make "memory gaps" and form disordered (unstable) social memory.

Based on the identified targets, the author proposed a construct as a tool of analysis aimed at identifying the reception of the past in contemporary cultural practices. In cognitive-conceptual space, a structural model of the social amnesia concept is built, which includes the phenomena of memory, forgetting, and archetype. Thus, the authors construct suggests the following a logical sequence of analysis:

- The logic of transformation of social memory in the cultural and historical context;

- Semantics manifestations of social amnesia in the reception practices of the past;

- Traumatic experiences of the past and the phenomenon of nostalgia in the discursive space of social amnesia; and

- Social amnesia in the coordinates of knowledge of the past.

Society in nature is "forced" to create a collective memory, which is the main mechanism of cultural unity. In addition, it is needed to overcome the limitations of individual existence. Social memory exists in a variety of phenomena, which are included in its structure at different levels of social reality and acts as a complex self-organizing process of selection, preservation, and reproduction of social systems of information on experiences and activities of human relations. Configuration manifestations of social memory in the characteristics of the national historical process in the form of its cyclically-wave nature show that periodically lost contents of memory can go back to history in processed form, in response to requests from the era.

Cyclically-wave nature of manifestations of social memory due to the fact that periods of activation of the collective memory are directly related to the events of the past and take on a symbolic significance, weaving in subsequent events. Images of the past are designed and recreated in the interaction of people, and her memory associated with the differentiation of the past and the future. At the same, oblivion as a cultural phenomenon is a form of representation of the past in the present, one of the modes of temporality of human being and society. The problem of the relation of memory and forgetting in a cultural context is of particular relevance in the transition, crisis era.

As memory serves as "the guardian of the past" and as a repository of information about the past, the history, which reveals the memory, is often associated with its loss or nostalgia for the past. As a result, social memory includes not only the processes of remembering, but of forgetting.

The problems of social upheaval in the context of collective memory and historical experience are largely due to the fact the twentieth century entered national history as "the age of disasters". Historical memory along with historical consciousness provides the processing and translation of the socio-cultural and event-national information from the past to the present - in the future.

In general, logic transformations of social memory in contemporary Russian society and its deformation occur in the trajectories of interaction of past and present. The difference between history and historical memory as an integral part of social memory is how to interpret the possibility of knowing the remaining time in the past. Deformation of the same social memory in the trajectories of past and present interactions due to the fact that memory is selective and often personified, and through evaluation of specific historical figures forms certain impressions, judgments and opinions.

Mass conversion of a human being and a society to an artificial past and deformed social memory accompanied by the construction of myths and Social mythology. In the context of updating the mythological models in ordinary consciousness formed a mental map "of the past", which is popular in a massification of historical concepts and their adaptation to the normative power-media-format single information space.

The fact of sociocultural reality becomes an extension of exposure to political mobilization, followed by the introduction of new information and communication technologies used in everyday political practice in the conditions of the information society. At the same time, there is a deliberate distortion (falsification) of the past, when historical events, the life, and deeds of politicians are deprived of any meaning and credibility, causes, and consequences of events, as well as the creation of fictional pseudo-pseudo-events and processes.

"The historical past of the constructed" in modern Russian society remains fragile. No agreement on the desired 
future of the country, hence the debate about the historical past. Formed historical narrative power, due to its political and ideological motivations claims. Depending on the political system, "singled out" specific historical memory blocks required for the formation of a certain ideological model.

Political and ideological bias in the cultural practices of the past experience of the reception due to the fact that the history of the Ring road is accumulated in the complex process of real properties and regularities of social being and social development, which is carried out in a specific context imperious. Front desk experience of the past is its perception, learning, interpretation, including in cultural practices to use in the new socio-political, historical, and cultural circumstances. Cultural practices of reception experience of the past due to the fact that at present the historical memory and past experience are essential characteristic lifestyle of people in many ways determines their attitudes and behaviour indirectly has a very powerful influence on their minds, thereby prejudice to the nature and methods of solving social problems.

Socio-cultural conditions and factors of manifestations in Russian society of social amnesia because social memory, translate the value-semantic content of the past, allow the subjects for identification of their existence with the existence of the previous generation. Through these meanings are reflected in the minds and actions of its subjects, made communication processes. Semantic relationship of actualization of the past and distribution of social amnesia occur in an environment where domestic intellectual elite, unable to reach a consensus on the future of the country, and continues to argue about the past, designing it in different ways.

After a reception by socio-cultural practices, the past is part of the present, but owing to the contradictory perception and interpretation of ambiguous political elites and various social groups, events, stories, and images of the past, which make "memory gaps" and form a disordered (unstable) social memory. Semantic relationship of actualization of the past and distribution of social amnesia in Russian society is due to the social transformation and modernization of our encounters archaic elements, traditionalism, and layers of mythological thinking.

A modern human being is immersed more and more into the oversaturated domestic media space. A human being not only faces with information and communication technologies and their uses, but its activity becomes a part of these technologies. In this case, media consumption as a social practice of using communication tools for development and symbolic content and implementation of social relationships and interactions.

The phenomenon of the modern media space in the Russian society is closely connected to the experience of the past. This is due to the fact that a set of meaningful and semantic phenomena in the coordinates of the functioning of social amnesia as the expansion of social unconsciousness, resulting in a distorted and partial loss of memory of the past in the society, in a sense of self-worth erosion of history and the presence of distorted experience the past.

Since the existence of society "without a past" is impossible, the nostalgic myth acts as a significant battery of norms, values, and traditions that are required to play the social conditions of life. Therefore, nostalgia as a sociocultural practice manifests itself in the discursive space of social amnesia. Dissatisfaction with life leads to that order, stability associated in the public mind with the Soviet era. Imperial symbols and mechanisms of social and mental function identification and currently, they are actively using the power in their PR-activities. At the same time, nostalgia as a sociocultural practice in the discursive space of social amnesia is inevitably superimposed on the distortion. Thus, partial loss of meaningful social experience and critical reflection in the collective memory of society are related to social forgetting, by deleting from the collective memory of certain socially significant historical facts and events, with the deliberate or unintentional falsification of the past.

Social knowledge is a set of social experience of the social subject, crystallized in a rational form and includes everything that is considered "knowledge" in society. In the space of production, distribution and consumption of knowledge of domestic social philosophy in the first place presents itself as a set of concepts explaining the laws of the transition state of society and its transformation. In the intellectual space, coexist ideas and theories, to use the terminology of "world-system" analysis, "mainstream", "periphery", and "deep periphery". First, it is the theory relating to the "mainstream" or "big theory"; inherently contain a claim to participate in the construction of ideological practices and building up social projects.

Social knowledge is largely due to the level of education. The changing social and political environment affects all institutions of society, especially to education. Educational practice as a complete historical socio-cultural organization of knowledge, thought and action, ensuring the reproduction of a particular social reality, is closely linked with the social knowledge in the conditions when a person becomes a witness of social transformation "simple" modernity.

Factor of social knowledge in relation to the historical experience, constructs a world of lost objects, ideas and images, and is due to the state of historical consciousness that, again, is closely linked to the political use of memory.

Manifestation of social amnesia in the practices of the Russian scientific community due to the fact that the current gap between public claims themselves historians pretend to strictly debug system of reproduction and propagation of 
knowledge, seeking to turn history into a "compulsory knowledge", comprising the real effect that produces historical knowledge in our days. This gap is supported by the fact that, on the one hand, historians themselves engaged not so much knowledge as such propaganda and discredited public education as the rationale and justification of new social and political institutions, which entered the project and of the historian.

Manifestation of social amnesia in the practices of the scientific community is also closely linked to the crisis of social sciences and humanities with the overall social and cultural crisis. In the context of globalization have been transformed and complicated social reality itself, change the model, it is displayed accordingly; there have been major changes in the research strategy of this reality. Social scientists, especially historians more rarely find themselves in the role of "public intellectuals" as a whole, though they usually fall to the public role of humanitarian and socio-historical knowledge.

The expansion of social amnesia in the context of scientific knowledge is also evident in "rewriting history". History today is re-written in order of power and therefore is more focused on their needs, which also operates in the plane of social amnesia. As a result, the mutual influence of social amnesia and practice of scientific (and pseudo-scientific) community due to the existing gap between public claims of historical science and real social and political circumstances of the Russian reality.

The nature and trajectory of the reception of the past in contemporary socio-cultural practices because today the "reasonable man" would seem to have the freedom to choose at each point of life and the freedom to overcome the inertia of history, including past experience imposed. However, history merciless to those who are not improving their meanings and cultural programs in accordance with the changing conditions. Russian "amnesia" society is not able to search for and find ways to overcome the increasingly complex problems in increasingly complex social world.

\section{References}

Assman, J., \& Beck, C.H. (2000). Religion und kulturelles Gedächtnis. München: Verlag.

Assmann, A. \& Conrad ,S. (Eds) (2010). Memory in a global age: Discourses, Practices and Tra-jectories / Eds. — Basingstoke; N.Y.: Palgrave Macmillan. XIV.

Assmann, A. \& Shortt, L. (Eds). (2012). Memory and political change Basingstoke; N.Y.: Palgrave Macmillan. XVIII.

Assmann, J. (1992). Das kulturelle Gedachtnis: Schrift, Erinnerung und politische Identitat in fruhen Hochkulturen. (p. 11). Munchen: Beck.

Bakiyeva, G. A. (2002). Social amnesia. Electronic Science and Education Journal "Polisfera". Retrieved from: http://polysphere. freenet. $\mathrm{kg} /$ по I / PSFIA12.htm

Connerton, P. (2009). How Modernity Forgets. (p.15). N.Y.: Cambridge University Press..

Douglas, M. (1986). How Institutions Think. Syracuse, NY: Syracu-se University Press.

Durkheim, E. (1997). The Division of Labor in Society. New York: Free Press.

Erll, A. (2008). Literature, Film, and the Mediality of Cultural Memo-ry. Cultural Memory. An International and Interdisciplinary Handbook. (p. 392). Eds. A. Erll, A. Nunning. Berlin; N.Y.: De Gruyter.

Halbwachs (1992). On collective memory. Chicago: The University of Chicago Press.

Historical Memory (2002). Continuity and Transformation. (pp. 13). Sotsis, No. 8.

Kleitman, A. (2009). Oblivion as a cultural phenomenon and the temporality of the subject. Fundamental problems of cultural studies: Col. of Art. of Congress Proceeding. (pp 79-80). Resp. Ed. D. L. Spivak. M .: Novyi Khronograph: Eidos.

Linde, C h. (2009). Working the past: Narrative and Institutio-nal Memory. N.Y.: Oxford University Press.

Linde, Ch. Life Stories (1993). The Creation of Coherence. N.Y.: Ox-ford University Press.

Logunova, L. Yu (2011). Socio-philosophical analysis of family and ancestral memory as a program of social inheritance. Abstract of the diss. of the ...Doctor of Philosophy Sciences. Kemerovo.

Lowenthal, D. (1985). The Past is a Foreign Country. Cambridge: Cambridge University Press.

Lowenthal, D. (1998). The Heritage Crusade and the Spoils of History. Cambridge: Cambridge University Press.

Loyko, O. T. (2014). Ontology of social memory. Abstract of the diss. of the ...Doctor of Philosophy Sciences. Krasnoyarsk.

Rozhdestvenskaya, E. \& Semenova, V. (2011). Social memory as an object of sociological study (pp. 27-28). Interaction. Interview. Interpretation. No. 6.

Solomina, I. Yu. (2005). Social Memory: structure and phenomena. Abstract of the diss. of the ...Candidate of Philosophy Sciences. Samara.

Suleim, S.R. (2006). Crises of Memory and the Second World War. Cambridge, MA; L.: Harvard University Press.

Toshchenko, Zh. T. (2011). Mankurtism as a form of historical amnesia. KENTAVR-PROBLEMA (Experience of philosophical and sociological analysis). Moscow: Novyi Khronograph.

Vasiliev, A. G. (2009). Memorialization and oblivion as the mechanisms of production of cultural unity and diversity. Fundamental problems of cultural studies: Col. of Art. of Congress Proceedings.( pp. 56-68). Resp. Ed. D. L. Spivak. M .: Novyi Khronograph.

Vasiliev, A.G. Memory studies: Unity Paradigm - Variety of Objects. Retrieved from: http://www.nlobooks.ru/node/2640\#_ftnref13

Zelizer, B. (1995). Reading the Past against the Grain: The Shape of Memory Studies (P. 214-239). Critical Studies in Mass Communica-tion. Vol. 12. № 2. 
ISSN 2039-2117 (online) ISSN 2039-9340 (print)
Mediterranean Journal of Social Sciences MCSER Publishing, Rome-Italy
Vol 6 No $3 \mathrm{~S} 3$ May 2015 